\title{
Outcome after PSMA PET/CT based radiotherapy in patients with biochemical persistence or recurrence after radical prostatectomy
}

Nina-Sophie Schmidt-Hegemann ${ }^{1 *}\left(\mathbb{D}\right.$, Wolfgang Peter Fendler ${ }^{2}$, Harun Ilhan², Annika Herlemann ${ }^{3}$, Alexander Buchner ${ }^{3}$, Christian Stief ${ }^{3}$, Chukwuka Eze $^{1}$, Paul Rogowski ${ }^{1}$, Minglun Li ${ }^{1}$, Peter Bartenstein ${ }^{2}$, Ute Ganswindt ${ }^{4}$ and Claus Belka ${ }^{1,5}$

\begin{abstract}
Background: PSMA PET/CT visualises prostate cancer residual disease or recurrence at lower PSA levels compared to conventional imaging and results in a change of treatment in a remarkable high number of patients. Radiotherapy with dose escalation to the former prostate bed has been associated with improved biochemical recurrence-free survival. Thus, it can be hypothesised that PSMA PET/CT-based radiotherapy might improve the prognosis of these patients.

Methods: One hundred twenty-nine patients underwent PSMA PET/CT due to biochemical persistence (52\%) or recurrence (48\%) after radical prostatectomy without evidence of distant metastases (February 2014-May 2017) and received PSMA PET/CT-based radiotherapy. Biochemical recurrence free survival (PSA $\leq 0.2 \mathrm{ng} / \mathrm{ml}$ ) was defined as the study endpoint.
\end{abstract}

Results: Patients with biochemical persistence were significantly more often high-risk patients with significantly shorter time interval before PSMA PET/CT than patients with biochemical recurrence. Patients with biochemical recurrence had significantly more often no evidence of disease or local recurrence only in PSMA PET/CT, whereas patients with biochemical persistence had significantly more often lymph node involvement. Seventy-three patients were started on antiandrogen therapy prior to radiotherapy due to macroscopic disease in PSMA PET/CT. Cumulatively, 70 (66-70.6) Gy was delivered to local macroscopic tumor, 66 (63-66) Gy to the prostate fossa, 61.6 (53.2-66) Gy to PET-positive lymph nodes and 50.4 (45-52.3) Gy to lymphatic pathways. Median PSA after radiotherapy was $0.07 \mathrm{ng} / \mathrm{ml}$ with $74 \%$ of patients having a PSA $\leq 0.1 \mathrm{ng} / \mathrm{ml}$. After a median follow-up of 20 months, median PSA was $0.07 \mathrm{ng} / \mathrm{ml}$ with ongoing antiandrogen therapy in 30 patients. PET-positive patients without antiandrogen therapy at last follow-up (45 patients) had a median PSA of $0.05 \mathrm{ng} / \mathrm{ml}$ with $89 \%$ of all patients, $94 \%$ of patients with biochemical recurrence and $82 \%$ of patients with biochemical persistence having a PSA $\leq 0.2 \mathrm{ng} / \mathrm{ml}$. Post-radiotherapy PSA $\leq 0.1 \mathrm{ng} / \mathrm{ml}$ and biochemical recurrence vs. persistence were significantly associated with a PSA $\leq 0.2 \mathrm{ng} / \mathrm{ml}$ at last follow-up.

Conclusions: PSMA PET/CT-based radiotherapy is an effective local salvage treatment option with significant PSA response in patients with biochemical recurrence or persistence after radical prostatectomy leading to deferral of long-term ADT or systemic therapy.

Keywords: Prostate cancer, PSMA PET/CT, Biochemical recurrence, Biochemical persistence, Radiotherapy

\footnotetext{
* Correspondence: Nina-Sophie.Hegemann@med.uni-muenchen.de

'Department of Radiation Oncology, University Hospital, LMU Munich,

Marchioninistr. 15, 81377 Munich, Germany

Full list of author information is available at the end of the article
} 


\section{Background}

${ }^{68}$ Ga-PSMA-HBED-CC ( ${ }^{68} \mathrm{Ga}$-PSMA) positron emission tomography/computed tomography (PET/CT) has emerged as the gold standard in staging prostate cancer patients with biochemical persistence or recurrence after radical prostatectomy compared to conventional imaging like computed tomography (CT) or magnetic resonance imaging (MRI) [1, 2] and choline PET/CT [3]. PSMA $\mathrm{PET} / \mathrm{CT}$ results in a modification of treatment e.g. addition of antiandrogen therapy (ADT), enlargement of the irradiated volume or even omission of radiotherapy in the event of advanced, metastatic disease in a remarkable high number of patients (33.8-76\%) with biochemical persistence or recurrence [4-10]. Unlike conventional imaging, PET with ${ }^{68} \mathrm{Ga}$-PSMA offers the unique possibility of visualising prostate cancer residual disease or recurrence at very low prostate-specific antigen (PSA) levels with $58.3 \%$ of PET-positive results found in a PSA range of 0.51-1.0 ng/ml [11-16]. Data stemming from retrospective dose escalation studies in patients with biochemical recurrence after radical prostatectomy confirmed that a higher radiation dose is significantly associated with a risk reduction in biochemical failure [17] and was not associated with a difference in acute grade 2 and 3 genitourinary or gastrointestinal toxicity in a single randomised study - SAKK 09/10 when irradiating the former prostate bed with 64 Gy vs. 70 Gy [18]. Since the advent of PSMA PET/CT, dose escalation to macroscopic tumor residual disease or recurrence is now more precisely possible and is potentially associated with a further improvement of biochemical recurrence-free survival. Currently, there is paucity of data regarding outcome after PSMA PET/ CT-based surgical [19-21] or radiotherapeutic treatment [22-27] in patients with persistent or recurrent prostate cancer. Since February 2014, offering PSMA PET/CT to all patients with recurrent or persistent prostate cancer after radical prostatectomy at our department, we evaluated the outcome following PSMA PET/CTbased radiotherapy.

\section{Methods}

\section{Study population}

In February 2014, ${ }^{68} \mathrm{Ga}$-PSMA PET/CT prior to radiotherapy was introduced at our department as the standard diagnostic staging tool routinely utilised in prostate cancer patients. A total of 176 consecutive patients underwent PSMA PET/CT prior to radiotherapy. 129/176 (73\%) patients received PSMA PET/CT due to biochemical persistence $(52 \%)$ or recurrence $(48 \%)$ after radical prostatectomy without evidence of distant metastases (Table 1). 47/176 (27\%) patients were excluded from the analysis: In 20/47 patients PSMA PET/CT was performed in the
Table 1 Patients' characteristics

\begin{tabular}{|c|c|c|c|}
\hline & All patients & PSA relapse & PSA persistence \\
\hline $\mathrm{N}$ & 129 & 62 & 67 \\
\hline Median age & $72(47-83)$ & $74(50-83)$ & $70(47-83)$ \\
\hline \multicolumn{4}{|l|}{ Tumor stage } \\
\hline pT2 & $43(33 \%)$ & $35(57 \%)$ & $8(12 \%)$ \\
\hline рT3a & $36(28 \%)$ & $17(27 \%)$ & $19(28 \%)$ \\
\hline pT3b & $48(37 \%)$ & $8(13 \%)$ & $40(60 \%)$ \\
\hline pT4 & $2(2 \%)$ & $2(3 \%)$ & - \\
\hline \multicolumn{4}{|l|}{ Nodal stage } \\
\hline pNO & $79(61 \%)$ & $46(74 \%)$ & $33(49 \%)$ \\
\hline pN1 & 37 (29\%) & $8(13 \%)$ & $29(43 \%)$ \\
\hline $\mathrm{pNx} / \mathrm{cNO}$ & $13(10 \%)$ & $8(13 \%)$ & $5(8 \%)$ \\
\hline Positive surgical margins & $60(47 \%)$ & $16(26 \%)$ & $44(66 \%)$ \\
\hline \multicolumn{4}{|l|}{ Gleason score } \\
\hline $6-7$ & $70(54 \%)$ & $44(71 \%)$ & $26(39 \%)$ \\
\hline $8-9$ & $59(46 \%)$ & $18(29 \%)$ & $41(61 \%)$ \\
\hline Median PSA at RPE & $\begin{array}{l}10.85 \\
(2.37-190)\end{array}$ & $\begin{array}{l}8.55 \\
(2.37-48)\end{array}$ & $\begin{array}{l}18.05 \\
(3.99-190)\end{array}$ \\
\hline Postoperative PSA & $\begin{array}{l}0.12 \\
(<0.03-40.13)\end{array}$ & $<0.03$ & $\begin{array}{l}0.47 \\
(0.08-40.13)\end{array}$ \\
\hline Months since RPE & $33(2-192)$ & $61(9-192)$ & $8(2-94)$ \\
\hline $\begin{array}{l}\text { Median PSA at PSMA } \\
\text { PET/CT }\end{array}$ & $\begin{array}{l}0.62 \\
(0.13-40.13)\end{array}$ & $\begin{array}{l}0.44 \\
(0.15-6.24)\end{array}$ & $\begin{array}{l}0.90 \\
(0.13-40.13)\end{array}$ \\
\hline $\begin{array}{l}\text { Median PSA at PSMA } \\
\text { PET/CT in PET positive pts }\end{array}$ & $\begin{array}{l}1.09 \\
(0.14-40.13)\end{array}$ & $\begin{array}{l}0.78 \\
(0.27-6.24)\end{array}$ & $\begin{array}{l}1.6 \\
(0.14-40.13)\end{array}$ \\
\hline $\begin{array}{l}\text { Median PSA at PSMA } \\
\mathrm{PET} / \mathrm{CT} \text { in PET negative pts }\end{array}$ & $\begin{array}{l}0.3 \\
(0.13-3.24)\end{array}$ & $\begin{array}{l}0.3 \\
(0.13-3.24)\end{array}$ & $\begin{array}{l}0.34 \\
(0.13-1.33)\end{array}$ \\
\hline \multicolumn{4}{|l|}{ PSMA PET/CT result } \\
\hline Negative & $51(39 \%)$ & $31(50 \%)$ & $20(30 \%)$ \\
\hline Fossa recurrence only & $24(19 \%)$ & $16(26 \%)$ & $8(12 \%)$ \\
\hline $\begin{array}{l}\text { Lymph node positive } \\
\text { only }\end{array}$ & $42(33 \%)$ & $12(19 \%)$ & $30(45 \%)$ \\
\hline $\begin{array}{l}\text { Fossa and lymph node } \\
\text { recurrence }\end{array}$ & $12(9 \%)$ & $3(5 \%)$ & $9(13 \%)$ \\
\hline
\end{tabular}

Pts patients, PSA prostate specific antigen, RPE radical prostatectomy, PSMA PET/CT prostate-specific membrane antigen positron emission tomography/computed tomography

primary setting and in 27/47 patients distant metastatic disease was diagnosed. All patients provided written informed consent to undergo ${ }^{68} \mathrm{Ga}$-PSMA PET/CT. This retrospective analysis was performed in compliance with the principles of the Declaration of Helsinki and its subsequent amendments [28] and was approved by the Ethics Committee of our Medical Faculty.

\section{Treatment application and follow up}

All patients received PSMA PET/CT as staging prior to radiotherapy. Treatment management following PSMA PET, e.g. initiation of ADT for PET-positive results, treatment of pelvic lymphatic pathways and simultaneous 
boost volumes to local recurrence or lymph node recurrence supplementary to the irradiation of former prostate was documented for each patient. Follow-up examination was first performed 3 months after irradiation and then every six to 12 months. Follow-up time was defined as the interval in months between radiotherapy and the last recorded PSA.

\section{PSMA ligand and PET/CT imaging}

PSMA-HBED-CC was radiolabelled with ${ }^{68} \mathrm{Ga}^{3+}$ from a ${ }^{68} \mathrm{Ge} /{ }^{68} \mathrm{Ga}$ generator system (GalliaPharm, Eckert \& Ziegler AG, Berlin, Germany) using an automated synthesis module (GRP, Scintomics GmbH, Munich, Germany) and pre-packed cassettes (ABX $\mathrm{GmbH}$, Radeberg, Germany) as described previously for a different PSMA ligand by Weineisen et al. [29]. ${ }^{68}$ Ga-PSMA PET/ CT images extending from the base of the skull to the mid-thigh were acquired. PET/CT scan was obtained with intravenous injection of iodine-containing contrast agent (Ultravist 300, Bayer Pharma AG, Berlin, Germany; or Imeron 300, Bracco, Konstanz; $2.5 \mathrm{~mL} / \mathrm{s}$; in portal venous phase) $60 \mathrm{~min}$ after almost simultaneous intravenous administration of $20 \mathrm{mg}$ furosemide and ${ }^{68} \mathrm{Ga}$-PSMA (mean 205 megabecquerel (MBq)). Directly prior to the $\mathrm{PET} / \mathrm{CT}$ scan, patients were implored to empty their bladders to minimise tracer accumulation.

\section{Image interpretation}

$\mathrm{PET} / \mathrm{CT}$ was interpreted by a consensus read by one nuclear medicine physician and one radiologist. Location of lesions was each determined by CT. PET-positive lesions were visually identified by ${ }^{68} \mathrm{Ga}$-PSMA uptake above background and not associated with the physiologic uptake. CT-positive nodes were defined by increased short axis diameter, loss of fatty hilum, or increased contrast enhancement. Local recurrence was identified by ${ }^{68} \mathrm{Ga}$ PSMA uptake and/or increased contrast enhancement in the prostate bed [30].

\section{Radiotherapy treatment}

Planning CT was done in supine position. Patients were advised to have a full bladder and an empty rectum. All patients received radiotherapy with intensity modulated RT (IMRT) or volumetric arc therapy (VMAT) and image-guided RT (IGRT) techniques (2-5 times/week) using cone-beam CTs. Target delineation was performed according to the Radiation Therapy Oncology Group (RTOG) atlas for salvage prostate cancer. The clinical target volume (CTV) of the former prostate gland is defined superiorly as $5 \mathrm{~mm}$ above the inferior border of the vas deferens remnant, inferiorly as above the top of penile bulb, anteriorly by the pubic symphysis, posteriorly by the anterior rectum and laterally by the medial edge of the obturator internus muscle. Planning target volume (PTV) was derived by expanding the CTV by a 5-7 mm margin in all directions. Generally, an overall dose of 66 Gy with 2 Gy per fraction was applied to the prostate bed and 50.4 Gy with 1.8 Gy per fraction to the lymphatic pathways when PET-positive nodal involvement was detected. PET-positive pelvic lymph nodes were treated with a simultaneous-integrated boost (1.85-2.2 Gy per fraction). Likewise, a simultaneous integrated/sequential boost (2.0-2.14 Gy per fraction) was applied in case of local recurrence in PSMA PET/ CT. The delineation of the gross tumor volume (GTV), i.e. local recurrence or suspicious lymph, nodes was based on 68Ga-PSMA uptake above background and increased contrast enhancement in the prostate bed and on increased short axis diameter, loss of fatty hilum, or increased contrast enhancement of the respective lymph nodes.

\section{Statistical analysis}

For statistical analysis, SPSS Statistics 24 (IBM, New York, USA) was used. Time to event data was calculated using the Kaplan-Meier method. Differences between subgroups were compared using log rank test with a $p$ value of $<0.05$ considered statistically significant. Uniand multivariate logistic regression analysis was used to identify predictors for treatment response.

\section{Results}

\section{Patients' characteristics and PSMA PET results}

One hundred twenty-nine consecutive patients were included in this retrospective analysis on outcome after PSMA PET/CT-based radiotherapy for biochemical persistence $(48 \%)$ or recurrence $(52 \%)$ following radical prostatectomy. Evidence of metastatic disease was considered an exclusion criterion. Patients with biochemical persistence were significantly more often high-risk patients with higher overall pathologic tumor stage $(60 \%$ pT3b; $p<0.05)$, pathologic pelvic lymph node involvement (43\% vs. $13 \%$ pN1; $p<0.05)$, positive surgical margins (66\% vs. $26 \% ; p<0.05)$ and higher Gleason Score $8-9$ (61\% vs. $29 \% \% ; p<0.05)$. Biochemical relapse was predominantly associated with low- to intermediate-risk [pT2 (57\%), pN0 (74\%) and Gleason Score 6-7 (71\%)]. All patients with biochemical recurrence had a nondetectable PSA postoperatively and a longer time interval until PSMA PET/CT vs. patients with biochemical persistence (61 vs. 8 months; $p<0.05)$. Overall, most patients (78/129; 60\%) had PET-positive findings. Patients with biochemical recurrence were significantly more often PSMA PET negative (50\% vs. 30\%) or if PSMA PET positive, they showed more often evidence of local recurrence $(26 \%$ vs. $12 \% ; p<0.05)$. On the other hand, patients with biochemical persistence had significantly more often PET-positive lymph nodes with 
(13\% vs. $5 \%)$ or without evidence of macroscopic tumour in the prostate bed (45\% vs. $19 \%)$. A negative PSMA PET scan was significantly associated with lower PSA levels: $76 \%$ of these patients had a PSA level $\leq 0.5 \mathrm{ng} /$ $\mathrm{ml}$ compared to patients with a positive scan with $74 \%$ of these patients having PSA levels $>0.5 \mathrm{ng} / \mathrm{ml}$. Baseline patients' characteristics are shown in Table 1.

\section{Management of PET-positive lesions and patients' outcome}

Androgen deprivation therapy (ADT) prior to radiotherapy was initiated in PET-positive findings (73/129). Five patients refused ADT. Fifty-nine percent (43/73) of these patients discontinued ADT after a median duration of 5 (2-25) months. All patients received VMAT- or IMRTbased radiotherapy to a median total dose of 66 (63-66) Gy to the prostate bed and 50.4 (45-52.3) Gy to the lymphatic pathways when PET-positive nodal involvement was detected with simultaneous integrated boost (SIB) to PET-positive lymph nodes (median dose $61.6 \mathrm{~Gy}$; 53.2-66 Gy) (Fig. 1). In the case of local tumour recurrence/persistence, a SIB was delivered to a median total dose of 70 (66-70.6) Gy.

Median follow-up was 20 months (3-42). Median post-radiotherapy PSA was $0.07 \mathrm{ng} / \mathrm{ml}(<0.03-13.71)$ with $74 \%$ of patients presenting with a PSA $\leq 0.1 \mathrm{ng} / \mathrm{ml}$ and $81 \%$ with a PSA $\leq 0.2 \mathrm{ng} / \mathrm{ml}$. At last median followup, median PSA was $0.07 \mathrm{ng} / \mathrm{ml}(<0.03-35)$ with $82 \%$ of all patients having a PSA $\leq 0.1 \mathrm{ng} / \mathrm{ml}$ and $84 \%$ a PSA $\leq 0.2 \mathrm{ng} / \mathrm{ml}$ (Fig. 2a). There were 30 (41\%) patients with ongoing ADT after a median follow-up of 20 months with $79 \% / 83 \%$ having a PSA $\leq 0.1 / 0.2 \mathrm{ng} / \mathrm{ml}$, respectively. Patients without ongoing ADT (91 patients) had a median PSA of $0.07 \mathrm{ng} / \mathrm{ml}(<0.03-35)$ with $83 \% / 85 \%$ presenting with a PSA $\leq 0.1 / 0.2 \mathrm{ng} / \mathrm{ml}$, respectively (Fig. $2 \mathrm{~b}$ ). PETpositive patients with discontinued or refused ADT at last follow-up (45 patients; 58\%) had a median PSA of $0.05 \mathrm{ng} / \mathrm{ml}(<0.03-35)$ with $89 \%$ of the entire cohort, $94 \%$ of the subgroup with biochemical recurrence and $82 \%$ with biochemical persistence having a PSA $\leq 0.2 \mathrm{ng} / \mathrm{ml}$ $(p=0.019$; Fig. $2 \mathrm{~d})$. ADT at last follow-up was more often applied in the subgroup of patients with biochemical persistence than biochemical recurrence (93\% vs. $7 \%$; $p<0.05)$. Distant metastases at last follow-up were only detected in the subgroup with biochemical persistence $(14 / 67 ; 21 \%)$. At the time of last analysis, all patients were alive. Treatment characteristics and PSA response are shown in Table 2 and Fig. 2.

\section{Factors predicting PSA response at last follow-up}

An uni- and multivariate analysis was conducted to assess whether there was an association between tumour specific variables and PSMA PET/CT imaging results and a PSA $\leq 0.2 \mathrm{ng} / \mathrm{ml}$ at last follow-up. This was first studied in all 129 patients including all 30 patients on ADT at last follow-up (Table 3) and was repeated due to possible confounding bias in patients without ADT (99 patients; data not shown). Regardless of ADT usage at last follow-up, there was no association between a PSA $\leq 0.2 \mathrm{ng} / \mathrm{ml}$ at last follow-up and the following factors [ADT at time of irradiation, pre-RT PSA $\leq />0.5 \mathrm{ng} /$ $\mathrm{ml}$, Gleason Score (6-7 vs. 8-9), pT- and pN-stage, surgical margins (positive vs. negative), PSMA PET result (negative or fossa recurrence only vs. PET-positive lymph nodes), PSMA PET result (positive vs. negative), overall dose $\leq 66.6 \mathrm{~Gy}$ vs. $>66 \mathrm{~Gy}$ to the prostate fossa and overall dose $\leq 50.4 \mathrm{~Gy}$ vs. $>50.4 \mathrm{~Gy}$ to pelvic lymph nodes]. A post-radiotherapy $\mathrm{PSA} \leq 0.1 \mathrm{ng} / \mathrm{ml}$ and biochemical recurrence vs. persistence were significantly associated with a PSA $\leq 0.2 \mathrm{ng} / \mathrm{ml}$ at last follow-up irrespective of ongoing ADT. On multivariate analysis, a significant association between post-radiotherapy $\mathrm{PSA} \leq 0.1 \mathrm{ng} / \mathrm{ml}$ and PSA $\leq 0.2 \mathrm{ng} / \mathrm{ml}$ at last follow-up was observed irrespective of the study population.

\section{Discussion}

PSMA PET/CT is currently the best available imaging technique to differentiate local relapse in the prostate bed, pelvic lymph node metastases or even metastatic disease in patients with biochemical persistence or recurrence [31]. Particularly, in patients considered for salvage radiation treatment, PSMA PET/CT has a high
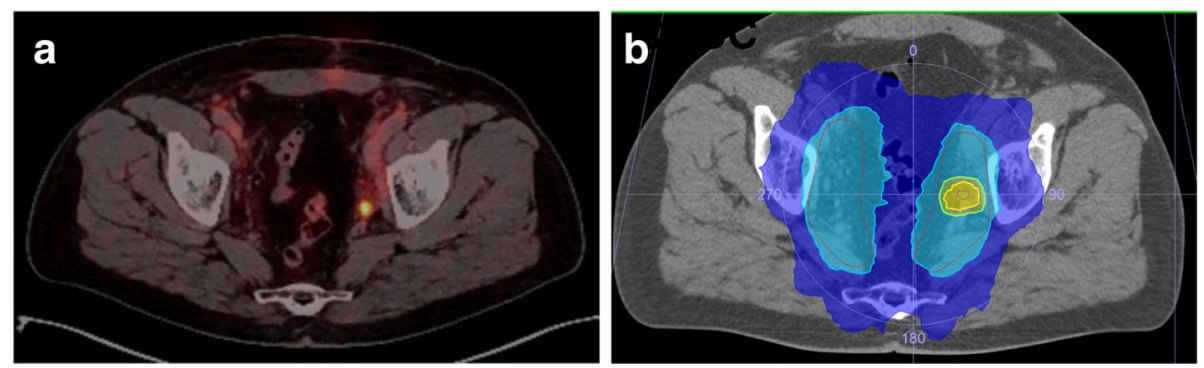

Fig. $1{ }^{68} \mathrm{Ga}$-PSMA PET/CT (a) and target volume with simultaneously integrated boost volume (b) to PET-positive lymph node 

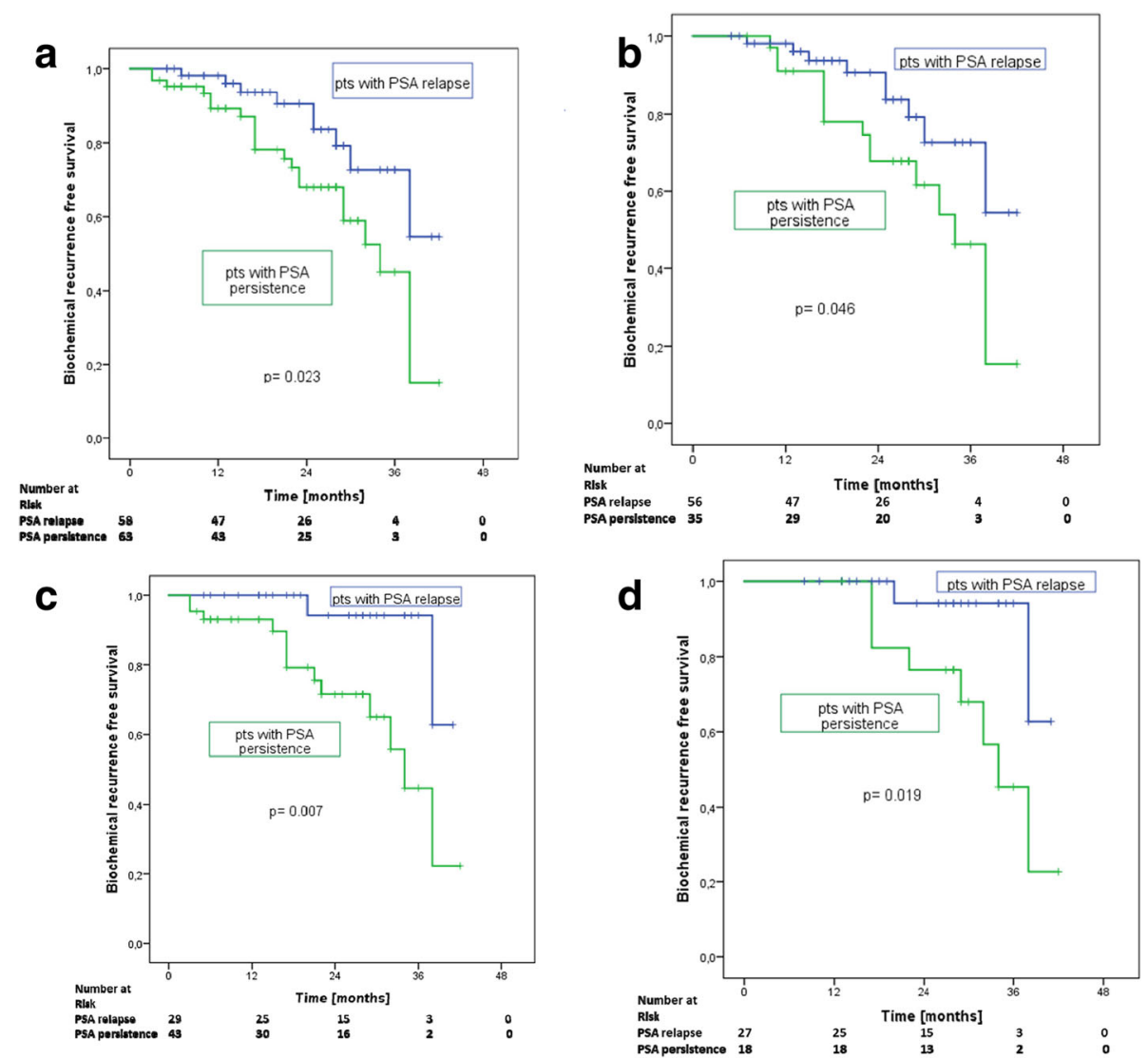

Fig. 2 a Biochemical recurrence free survival $(\leq 0.2 \mathrm{ng} / \mathrm{ml})$ in all patients (PSA persistence vs. PSA recurrence) at last follow-up. b Biochemical recurrence free survival $(\leq 0.2 \mathrm{ng} / \mathrm{ml})$ in all patients without antiandrogen therapy (PSA persistence vs. PSA recurrence) at last follow-up. $\mathbf{c}$ Biochemical recurrence free survival ( $\leq 0.2 \mathrm{ng} / \mathrm{ml}$ ) in all PET-positive patients (PSA persistence vs. PSA recurrence) at last follow-up. $\mathbf{d}$ Biochemical recurrence free survival $(\leq 0.2 \mathrm{ng} / \mathrm{ml}$ ) in all PET-positive patients without antiandrogen therapy (PSA persistence vs. PSA recurrence) at last follow-up

detection rate of prostate cancer lesions outside the prostatic fossa [15], corresponding to the number of men failing after salvage irradiation of the prostate fossa. Thus in $5 \% / 19 \%$ of our patients treated due to biochemical failure, PSMA PET/CT revealed pelvic nodal involvement with/without local recurrence, respectively. As expected, patients with biochemical persistence being significantly more high-risk patients had a significantly higher rate of PET-positive pelvic lymph node metastases with/without local disease (13\%/45\%). This leads to a remarkable change in treatment e.g. the modification of radiation fields, dose escalation to macroscopic tumour lesions and initiation of ADT, as already extensively studied in current literature [4-9].

Furthermore, PSMA PET/CT is especially sensitive in identifying tumour recurrence at PSA levels well below $1.0 \mathrm{ng} / \mathrm{ml}$ [12], enabling radiotherapy initiation at PSA levels that are still considered curable [32]. Currently, no general recommendation for a PSA cut-off prior to postoperative staging with PSMA PET/CT exists, although some data suggest a PSA of $0.83 \mathrm{ng} / \mathrm{ml}$ as an optimal cut-off value [33]. In comparison, PET-positive findings were seen in our cohort at a slightly lower median PSA $(0.78 \mathrm{ng} / \mathrm{ml})$ in patients with biochemical recurrence vs. biochemical persistence (median PSA $1.6 \mathrm{ng} / \mathrm{ml}$ ).

All patients with biochemical recurrence or persistence underwent PSMA PET/CT-based radiation treatment: absence of PET-positive disease resulted in irradiation of the prostate bed exclusively, whereas in the case of local recurrence a SIB was delivered. Additionally, presence of PET-positive pelvic lymph nodes resulted in irradiation of the pelvic basin with SIB to the involved nodes.

Extrapolated from data for $\mathrm{pN}+$ patients treated with adjuvant radiotherapy and concurrent ADT [34, 35], ADT was recommended for 2 years with evidence of PET-positive lesions. Although, 73 patients were started on ADT, about two-thirds discontinued prematurely after a median time of $5(2-25)$ months due to patients' preferences.

Based on a median follow-up of 20 months and an overall number of 129 patients, our analysis shows the 
Table 2 Treatment and response

\begin{tabular}{llll}
\hline & $\begin{array}{l}\text { All } \\
\text { patients }\end{array}$ & $\begin{array}{l}\text { PSA } \\
\text { relapse }\end{array}$ & $\begin{array}{l}\text { PSA } \\
\text { persistence }\end{array}$ \\
\hline ADT & & & \\
$\begin{array}{l}\text { ADT with stop before } \\
\text { last follow up / duration } \\
\text { (months) }\end{array}$ & $\begin{array}{l}43 / 5 \\
(2-25)\end{array}$ & $\begin{array}{l}22 / 4.5 \\
(2-23)\end{array}$ & $\begin{array}{l}21 / 5.5 \\
(2-25)\end{array}$ \\
$\begin{array}{l}\text { Ongoing ADT at last } \\
\text { follow up }\end{array}$ & 30 & 3 & 27 \\
$\begin{array}{l}\text { No ADT } \\
\text { Median PSA before RT }\end{array}$ & $\begin{array}{l}0.62 \\
(<0.03-40.13)\end{array}$ & $\begin{array}{l}(0.15-10.6) \\
(<0.03-40.13)\end{array}$
\end{tabular}

RT

$\begin{array}{ll}\text { Former Prostate } & 66 \text { Gy (63-66) } \\ \text { Lymphatic pathways } & 50.4 \text { Gy (45-52.3) } \\ \text { Local recurrence } & 70 \text { Gy (66-70.6) } \\ \text { PET pos. LN } & 61.6 \text { Gy (53.2-66) }\end{array}$

RT technique

VMAT/IMRT \& IGRT All pts.

Median Follow-up (months)

First PSA after RT

Median PSA

$P S A \leq 0.1 \mathrm{ng} / \mathrm{ml}$

PSA $\leq 0.2 \mathrm{ng} / \mathrm{ml}$

PSA at last median follow-up

\section{Median PSA \\ $P S A \leq 0.1 \mathrm{ng} / \mathrm{ml}$ \\ $P S A \leq 0.2 \mathrm{ng} / \mathrm{ml}$}

PSA at last median follow-up with ADT

Median PSA
PSA $\leq 0.1 \mathrm{ng} / \mathrm{ml}$
PSA $\leq 0.2 \mathrm{ng} / \mathrm{ml}$

PSA at last median follow-up without ADT

$$
\begin{aligned}
& \text { Median PSA } \\
& \text { PSA } \leq 0.1 \mathrm{ng} / \mathrm{ml} \\
& \text { PSA } \leq 0.2 \mathrm{ng} / \mathrm{ml}
\end{aligned}
$$

PSA at last median follow-up in PET pos. pts

Median PSA
PSA $\leq 0.1 \mathrm{ng} / \mathrm{ml}$
PSA $\leq 0.2 \mathrm{ng} / \mathrm{ml}$

PSA at last median follow-up in PET pos. pts without ADT
Table 2 Treatment and response (Continued)

\begin{tabular}{llll}
\hline & $\begin{array}{l}\text { All } \\
\text { patients }\end{array}$ & $\begin{array}{l}\text { PSA } \\
\text { relapse }\end{array}$ & $\begin{array}{l}\text { PSA } \\
\text { persistence }\end{array}$ \\
\hline Median PSA & 0.05 & 0.04 & 0.13 \\
& $(<0.03-35)$ & $(<0.03-0.46)$ & $(<0.03-35)$ \\
PSA $\leq 0.1 \mathrm{ng} / \mathrm{ml}$ & $89 \%$ & $94 \%$ & $82 \%$ \\
PSA $\leq 0.2 \mathrm{ng} / \mathrm{ml}$ & $89 \%$ & $94 \%$ & $82 \%$ \\
PSA at last follow-up & $n=49$ & $n=29$ & $n=20$ \\
in PET neg. pts & & & \\
Median PSA & 0.07 & 0.07 & 0.08 \\
& $(<0.03-3.23)$ & $(<0.03-1)$ & $(<0.03-3.23)$ \\
PSA $\leq 0.1 \mathrm{ng} / \mathrm{ml}$ & $78 \%$ & $79 \%$ & $77 \%$ \\
PSA $\leq 0.2 \mathrm{ng} / \mathrm{ml}$ & $83 \%$ & $87 \%$ & $77 \%$
\end{tabular}

Clinical Progress

Distant Metastases

14

PSA prostate specific antigen, $A D T$ androgen deprivation therapy, $L N$ lymph nodes, $R T$ radiation therapy, VMAT volumetric modulated arc therapy, IMRT intensity modulated radiotherapy, IGRT image guided radiotherapy

aPSA follow-up missing in eight patients

bPSA follow-up missing in four patients

high impact of PSMA PET/CT on oncologic outcome and is in accordance with the currently limited number of analyses on outcome after PSMA PET/CT-based radiotherapy in persistent or recurrent prostate cancer with mostly shorter follow-up [22-26]: Our analysis shows that there is a high rate and long-lasting treatment response to irradiation based on pre-treatment

Table 3 Association between treatment response (PSA $\leq 0.2 \mathrm{ng} / \mathrm{ml}$ )

\begin{tabular}{|c|c|c|}
\hline Association between treatment response and & $p$-Value ${ }^{a}$ & $p$-Value ${ }^{b}$ \\
\hline ADT at time of RT & 0.104 & 0.131 \\
\hline PRE-RT PSA $\leq />0.5 \mathrm{ng} / \mathrm{ml}$ & 0.226 & 0.188 \\
\hline Gleason Score (6-7 vs. 8-9) & 0.129 & 0.791 \\
\hline pT stage & 0.104 & 0.195 \\
\hline pN stage & 0.341 & 0.908 \\
\hline Surgical margins & 0.833 & 0.609 \\
\hline PSA after RT $\leq 0.1 \mathrm{ng} / \mathrm{ml}$ & 0.008 & 0.007 \\
\hline $\begin{array}{l}\text { PSMA PET result } \\
\text { (Negative or fossa recurrence only vs. } \\
\text { lymph node recurrence) }\end{array}$ & 0.623 & 0.999 \\
\hline $\begin{array}{l}\text { PSMA PET result } \\
\text { (positive vs. negative) }\end{array}$ & 0.263 & 0.693 \\
\hline $\begin{array}{l}\text { Dose escalation prostate fossa } \\
\leq 66.6 \mathrm{~Gy} \text { vs. }>66 \mathrm{~Gy}\end{array}$ & 0.324 & 0.122 \\
\hline $\begin{array}{l}\text { Dose escalation pelvic lymph nodes } \\
\leq 50.4 \text { Gy vs. }>50.4 G y\end{array}$ & 0.371 & 0.999 \\
\hline $\begin{array}{l}\text { RT indication (biochemical recurrence vs. } \\
\text { biochemical persistence) }\end{array}$ & 0.026 & 0.211 \\
\hline
\end{tabular}
at last follow-up and possibly interacting variables (logistic regression analysis, all patients)

PSA prostate specific antigen, ADT androgen deprivation therapy, PRE-RT PSA PSA pre-radiotherapy, $R T$ radiotherapy ${ }^{\mathrm{a}}$ univariate and ${ }^{\mathrm{b}}$ multivariate binary logistic regression analysis ${ }^{*} p<0.05$ statistically significant 
PSMA PET/CT in patients with biochemical recurrence or persistence with $84 \%$ presenting with a PSA $\leq 0.2 \mathrm{ng} /$ $\mathrm{ml}$ at a median follow-up of 20 months. When restricting the analysis to PET-positive patients without ADT at last follow-up (45 patients), the most challenging and interesting subgroup, $89 \%$ had a PSA $\leq 0.2 \mathrm{ng} / \mathrm{ml}$. Splitting this subgroup further into patients with biochemical recurrence vs. persistence, the number of patients with PSA $\leq 0.2 \mathrm{ng} / \mathrm{ml}$ after a median follow-up of 20 months becomes even more divergent: $94 \%$ of patients with biochemical recurrence and evidence of PET-positive disease without ADT at last median follow up had a PSA level $\leq 0.1 \mathrm{ng} / \mathrm{ml}$ and $\leq 0.2 \mathrm{ng} / \mathrm{ml}$ vs. $82 \%$ of patients with biochemical persistence having a PSA $\leq 0.2 \mathrm{ng} / \mathrm{ml}(p=0.019$; Fig. $2 \mathrm{~d})$. This mainly reflects the fact that men with biochemical recurrence in our cohort had significantly more local relapses within the prostate fossa compared to men with biochemical persistence with significantly more pelvic nodal involvement in PSMA PET/CT. Emmett et al. [23] likewise reported on treatment outcome from PSMA PET/CT informed salvage radiation treatment in men with rising PSA following radical prostatectomy: based on a shorter median follow-up of 10.5 months, they also saw a high number of treatment response to radiotherapy (29/36 patients; $83 \%)$ when disease was confined to prostate fossa compared to patients with PET-positive nodal involvement (16/26 patients; 61\%). Furthermore, the high number of $94 \%$ of PET-positive patients with biochemical recurrence having a PSA $\leq 0.1 \mathrm{ng} / \mathrm{ml}$ after 20 months in our cohort compares nicely to the analysis of Zschaeck et al. [22] on 20 recurrent high-risk prostate cancer patients with a median PSA of $0.15 \mathrm{ng} / \mathrm{ml}$ after a median follow-up of 29 months.

Achieving a post-radiotherapy PSA nadir $\leq 0.1 \mathrm{ng} / \mathrm{ml}$ and radiotherapy indication (biochemical recurrence vs. persistence) were the only factors associated with a PSA $\leq 0.2 \mathrm{ng} /$ $\mathrm{ml}$ at last follow-up in our cohort. This is in accordance with the recent data by Bartkowiak et al. [36] demonstrating that men with undetectable post-radiotherapy PSA have lower rates of metastases and a better overall survival. Unlike the findings by Emmett et al. [23] that PSMA PET result (negative or fossa recurrence only vs. PET-positive lymph nodes vs. distant metastases) is predictive of treatment response to salvage radiotherapy, we did not see any correlation between PSMA PET result (negative or fossa recurrence only vs. PET-positive lymph nodes) and biochemical recurrence-free survival. This is most likely to due to the fact, that we restricted our analysis to nonmetastasised patients in contrast to the study by Emmett et al. which included patients with metastatic disease. Furthermore, contrary to data from literature showing a strong association between pre-RT PSA and progressionfree survival [32, 36], there was no such association between pre-RT PSA $\leq />0.5 \mathrm{ng} / \mathrm{ml}$ and PSA $\leq 0.2 \mathrm{ng} / \mathrm{ml}$ at last follow-up in our cohort.

Our study has several limitations mainly as it is a retrospective study. Moreover, there was a low number of patients with biochemical recurrence that limits the statistical power of a multivariate analysis. Thus, a validation of our results within a larger cohort would be preferable.

Currently, PSMA PET/CT is the best diagnostic tool available for patients with rising PSA post-radical prostatectomy. Yet, it may still underestimate the true extent of disease in particular for the detection of small volume lymph nodes below $4 \mathrm{~mm}$ due to the inherent physical limitations of PET imaging $[1,37]$ as well as for lesions close to the prostate fossa overshadowed by the SUV and radioactivity concentration within the bladder $[38,39]$. The implementation of novel 18F-labeled PSMA tracers may overcome this issue because of its low clearance via the urinary tract. Consequently, one third of our PET-negative patients, all treated with irradiation to the prostate fossa, failed biochemically at last follow-up. Since all data available consistently document that PSA control is significantly better when radiotherapy is commenced as early as possible [32, 40, 41], it is nevertheless not justifiable to wait until PSA is in an optimal range or surpasses a cut-off for diagnostic assessment.

\section{Conclusions}

Currently, PSMA PET/CT is the best available imaging technique in patients with persistent or rising PSA after radical prostatectomy and detects a high number of lesions not confined to the prostate fossa. PSMA PET/ $\mathrm{CT}$ enables tailoring of radiation treatment with adaptation of irradiated volumes. After a median follow-up of 20 months, nearly $90 \%$ of men with PET-positive lesions without any ongoing antiandrogen therapy at last follow-up did not show any evidence of biochemical recurrence after PSMA PET/CT-based radiotherapy leading to a potential deferral of ADT or systemic therapy.

\footnotetext{
Abbreviations

${ }^{68} \mathrm{Ga}$-PSMA: ${ }^{68} \mathrm{Gallium}$-prostate-specific membrane antigen; ADT: Androgen deprivation therapy; CT: Computed tomography; CTV: Clinical target volume; GS: Gleason score; GTV: Gross tumor volume; Gy: Gray; IGRT: Image guided radiotherapy; IMRT: Intensity modulated radiotherapy; MBq: Megabecquerel; MRI: Magnetic resonance imaging; PCa: Prostate cancer; PET: Positron emission tomography; PET/CT: Positron emission tomography/computed tomography; PSA: Prostate specific antigen; pts.: Patients; PTV: Planning target volume; RT: Radiotherapy; SIB: Simultaneous integrated boost; VMAT: Volumetric modulated arc therapy
}

\section{Acknowledgements}

Not applicable.

Funding

No funding was received. 


\section{Availability of data and materials}

The datasets used and analyzed during the current study are available from the corresponding author on reasonable request.

\section{Authors' contributions}

$\mathrm{N}-\mathrm{SS}-\mathrm{H}$ and $\mathrm{CB}$ analysed and interpreted the data, performed the statistical analysis and were major contributors in writing the manuscript. UG and $A B$ helped with the statistical analysis and writing the manuscript. CS, CE, PR, $M L, W P F, H I, A H$ and $P B$ helped drafting the manuscript. All authors read and approved the final manuscript.

\section{Ethics approval and consent to participate}

All patients gave written consent to undergo ${ }^{68} \mathrm{Ga}$-PSMA PET/CT and radiotherapy. This retrospective analysis is in compliance with the principles of the Declaration of Helsinki and its subsequent amendments [28] and was approved by the local Ethics Committee.

\section{Consent for publication}

Not applicable.

\section{Competing interests}

The authors declare that they have no competing interests.

\section{Publisher's Note}

Springer Nature remains neutral with regard to jurisdictional claims in published maps and institutional affiliations.

\section{Author details}

'Department of Radiation Oncology, University Hospital, LMU Munich, Marchioninistr. 15, 81377 Munich, Germany. 'Department of Nuclear Medicine, University Hospital, LMU Munich, Munich, Germany. ${ }^{3}$ Department of Urology, University Hospital, LMU Munich, Munich, Germany. ${ }^{4}$ Department of Therapeutic Radiology and Oncology, Innsbruck Medical University, Anichstr. 35, A-6020 Innsbruck, Austria. ${ }^{5}$ German Cancer Consortium (DKTK), Munich, Germany.

Received: 8 January 2018 Accepted: 22 February 2018 Published online: 02 March 2018

\section{References}

1. Maurer T, Gschwend JE, Rauscher I, Souvatzoglou M, Haller B, Weirich G, et al. Diagnostic efficacy of (68)Gallium-PSMA positron emission tomography compared to conventional imaging for lymph node staging of 130 consecutive patients with intermediate to high risk prostate cancer. J Urol. 2016;195(5):1436-43.

2. Hernandez D, Salas D, Giménez D, Buitrago P, Esquena S, Palou J, et al. Pelvic MRI findings in relapsed prostate cancer after radical prostatectomy. Radiat Oncol. 2015:10(1):262.

3. Morigi JJ, Stricker PD, van Leeuwen PJ, Tang R, Ho B, Nguyen Q, et al. Prospective comparison of 18F-Fluoromethylcholine versus 68Ga-PSMA PET/ $\mathrm{CT}$ in prostate cancer patients who have rising PSA after curative treatment and are being considered for targeted therapy. JNM. 2015;56(8):1185-90.

4. Schiller K, Sauter K, Dewes S, Eiber M, Maurer T, Gschwend J, et al. Patterns of failure after radical prostatectomy in prostate cancer - implications for radiation therapy planning after (68)Ga-PSMA-PET imaging. EJNMMI. 2017:44:1656.

5. Sterzing F, Kratochwil C, Fiedler H, Katayama S, Habl G, Kopka K, et al. 68Ga-PSMA-11 PET/CT: a new technique with high potential for the radiotherapeutic management of prostate cancer patients. EJNMMI. 2016:43:34.

6. Afaq A, Alahmed S, Chen SH, Lengana T, Haroon A, Payne $H$, et al. (68)Ga-PSMA PET/CT impact on prostate cancer management. JNM. 2018;59(1):89-92.

7. Habl G, Sauter K, Schiller K, Dewes S, Maurer T, Eiber M, et al. (68) Ga-PSMA-PET for radiation treatment planning in prostate cancer recurrences after surgery: individualized medicine or new standard in salvage treatment. Prostate. 2017;77(8):920-7.

8. Albisinni S, Artigas C, Aoun F, Biaou I, Grosman J, Gil T, et al. Clinical impact of (68) Ga-prostate-specific membrane antigen (PSMA) positron emission tomography/computed tomography (PET/CT) in patients with prostate cancer with rising prostate-specific antigen after treatment with curative intent: preliminary analysis of a multidisciplinary approach. BJU Int. 2017;120(2):197-203.

9. Bluemel C, Linke F, Herrmann K, Simunovic I, Eiber M, Kestler C, et al. Impact of 68Ga-PSMA PET/CT on salvage radiotherapy planning in patients with prostate cancer and persisting PSA values or biochemical relapse after prostatectomy. EJNMMI Res. 2016;6(1):78.

10. Shakespeare TP. Effect of prostate-specific membrane antigen positron emission tomography on the decision-making of radiation oncologists. Radiat Oncol. 2015;10:233.

11. Afshar-Oromieh A, Zechmann C, Malcher A, Eder M, Eisenhut M, Linhart $H_{\text {, }}$ et al. Comparison of PET imaging with a 68Ga-labelled PSMA ligand and 18F-choline-based PET/CT for the diagnosis of recurrent prostate cancer. EJNMMI. 2014:41(1):11-20

12. Afshar-Oromieh A, Avtzi E, Giesel F, Holland-Letz T, Linhart $H$, Eder M, et al. The diagnostic value of PET/CT imaging with the 68Ga-labelled PSMA ligand HBED-CC in the diagnosis of recurrent prostate cancer. EJNMMI. 2015:42(2):197-209.

13. Eiber M, Maurer T, Souvatzoglou M, Beer AJ, Ruffani A, Haller B. Evaluation of hybrid 68Ga-PSMA-ligand PET/CT in 248 patients with biochemical recurrence after radical prostatectomy. JNM. 2015;56(5):668-74.

14. Giesel F, Fiedler H, Stefanova M, Sterzing F, Rius M, Kopka K, et al. PSMA PET/CT with Glu-urea-Lys-(Ahx)-[68Ga(HBED-CC)] versus 3D CT volumetric lymph node assessment in recurrent prostate cancer. EJNMML. 2015:42(12):1794-800

15. van Leeuwen PJ, Stricker P, Hruby G, Kneebone A, Ting F, Thompson B, et al. (68) Ga-PSMA has a high detection rate of prostate cancer recurrence outside the prostatic fossa in patients being considered for salvage radiation treatment. BJU Int. 2016;117(5):732-9.

16. Afshar-Oromieh A, Holland-Letz T, Giesel FL, Kratochwil C, Mier W, Haufe S, et al. Diagnostic performance of (68)Ga-PSMA-11 (HBED-CC) PET/CT in patients with recurrent prostate cancer: evaluation in 1007 patients. EJNMMI. 2017:44(8):1258-68.

17. Pisansky TM, Agrawal S, Hamstra DA, Koontz BF, Liauw SL, Efstathiou JA, et al. Salvage radiation therapy dose response for biochemical failure of prostate cancer after prostatectomy - a multi-institutional observational study. Int J Radiat Oncol Biol Phys. 2016;96(5):1046-53.

18. Ghadjar P, Hayoz S, Bernhard J, Zwahlen DR, Hölscher T, Gut P, et al. Acute toxicity and quality of life after dose-intensified salvage radiation therapy for biochemically recurrent prostate cancer after prostatectomy: first results of the randomized trial SAKK 09/10. J Clin Oncol. 2015;33(35):4158-66.

19. Schiavina R, Ceci F, Romagnoli D, Uprimny C, Brunocilla E, Borghesi M, et al. 68Ga-PSMA-PET/CT-guided salvage retroperitoneal lymph node dissection for disease relapse after radical prostatectomy for prostate cancer. Clin Genitourin Cancer. 2015;13(6):e415-7.

20. Siriwardana A, Thompson J, van Leeuwen PJ, Doig S, Kalsbeek A, Emmett L, et al. Initial multicentre experience of 68gallium-PSMA PET/CT guided robot-assisted salvage lymphadenectomy: acceptable safety profile but oncological benefit appears limited. BJU Int. 2017;120(5):673-81.

21. Maurer T, Weirich G, Schottelius M, Weineisen M, Frisch B, Okur A, et al. Prostate-specific membrane antigen-radioguided surgery for metastatic lymph nodes in prostate cancer. Eur Urol. 2015;68(3):530-4.

22. Zschaeck S, Wust P, Beck M, Wlodarczyk W, Kaul D, Rogasch J, et al. Intermediate-term outcome after PSMA-PET guided high-dose radiotherapy of recurrent high-risk prostate cancer patients. Radiat Oncol. 2017;12(1):140.

23. Emmett L, Van Leeuwen P, Nandurkar R, Scheltema MJ, Cusick T, Hruby G, et al. Treatment outcomes from (68)GaPSMA PET CT informed salvage radiation treatment in men with rising PSA following radical prostatectomy: prognostic value of a negative PSMA PET. J Nucl Med. 2017;58:1972.

24. Henkenberens C, Klot CA, Ross TL. 68Ga-PSMA ligand PET/CT-based radiotherapy in locally recurrent and recurrent oligometastatic prostate cancer: early efficacy after primary therapy. Strahlenther Onkol. 2016;192(7):431-9.

25. Henkenberens C, Von Klot CA, Ross TL, Bengel FM, Wester H-J, Hüper K, et al. 68Ga-PSMA ligand PET/CT-based radiotherapy for lymph node relapse of prostate cancer after primary therapy delays initiation of systemic therapy. Anticancer Res. 2017;37(3):1273-9.

26. Habl G, Straube C, Schiller K, Duma MN, Oechsner M, Kessel KA, et al. Oligometastases from prostate cancer: local treatment with stereotactic body radiotherapy (SBRT). BMC Cancer. 2017;17(1):361.

27. Pasqualetti F, Panichi M, Sainato A, Matteucci F, Galli L, Cocuzza P, et al. [18F]Choline PET/CT and stereotactic body radiotherapy on treatment 
decision making of oligometastatic prostate cancer patients: preliminary results. Radiat Oncol. 2016;11(1):9.

28. Association GAotWM. World Medical Association Declaration of Helsinki: ethical principles for medical research involving human subjects. J Am Coll Dent. 2014;81(3):14-8.

29. Weineisen M, Simecek J, Schottelius M, Schwaiger M, Wester H-J. Synthesis and preclinical evaluation of DOTAGA-conjugated PSMA ligands for functional imaging and endoradiotherapy of prostate cancer. EJNMMI Res. 2014;4(1):1-15.

30. Fendler WP, Eiber M, Beheshti M, Bomanji J, Ceci F, Cho S, et al. 68Ga-PSMA PET/CT: joint EANM and SNMMI procedure guideline for prostate cancer imaging: version 1.0. EJNMMI. 2017;44(6):1014-24.

31. Perera M, Papa N, Christidis D, Wetherell D, Hofman MS, Murphy DG, et al. Sensitivity, specificity, and predictors of positive 68Ga-prostate-specific membrane antigen positron emission tomography in advanced prostate cancer: a systematic review and meta-analysis. Eur Urol. 2016;70(6):926-37.

32. Tendulkar RD, Agrawal S, Gao T, Efstathiou JA, Pisansky TM, Michalski JM, et al. Contemporary update of a multi-institutional predictive nomogram for salvage radiotherapy after radical prostatectomy. J Clin Oncol. 2016;34(30):3648-54.

33. Ceci F, Uprimny C, Nilica B, Geraldo L, Kendler D, Kroiss A, et al. (68)Ga-PSMA PET/CT for restaging recurrent prostate cancer: which factors are associated with PET/CT detection rate? EJNMMI. 2015;42(8):1284-94.

34. Briganti A, Karnes RJ, Da Pozzo LF, Cozzarini C, Capitanio U, Gallina A, et al. Combination of adjuvant hormonal and radiation therapy significantly prolongs survival of patients with pT2-4 pN+ prostate cancer: results of a matched analysis. Eur Urol. 2011;59(5):832-40.

35. Abdollah F, Karnes RJ, Suardi N, Cozzarini C, Gandaglia G, Fossati N, et al. Impact of adjuvant radiotherapy on survival of patients with node-positive prostate cancer. J Clin Oncol. 2014;32(35):3939-47.

36. Bartkowiak D, Thamm R, Bottke D, Siegmann A, Böhmer D, Budach V, Wiegel T. Prostate-specific antigen after salvage radiotherapy for postprostatectomy biochemical recurrence predicts long-term outcome including overall survival. Acta Oncol. 2018;57(3):362-67.

37. van Leeuwen PJ, Emmett L, Ho B, Delprado W, Ting F, Nguyen Q, Stricker PD. Prospective evaluation of 68Gallium-prostate-specific membrane antigen positron emission tomography/computed tomography for preoperative lymph node staging in prostate cancer. BJU Int. 2017;119(2):209-15.

38. Afshar-Oromieh A, Sattler LP, Mier W, Hadaschik BA, Debus J, Holland-Letz T, et al. The clinical impact of additional late PET/CT imaging with 68Ga-PSMA-11 (HBED-CC) in the diagnosis of prostate cancer. JNM. 2017;58(5):750-5.

39. Derlin $\mathrm{T}$, Weiberg $\mathrm{D}$, von Klot $\mathrm{C}$, Wester $\mathrm{H}-\mathrm{J}$, Henkenberens $\mathrm{C}$, et al. 68Ga-PSMA I\&T PET/CT for assessment of prostate cancer: evaluation of image quality after forced diuresis and delayed imaging. Eur Radiol. 2016;26(12):4345-53.

40. Pfister D, Bolla M, Briganti A, Carroll P, Cozzarini C, Joniau S, et al. Early salvage radiotherapy following radical prostatectomy. Eur Urol. 2014;65(6):1034-43.

41. Taguchi S, Shiraishi K, Fukuhara H, Nakagawa K, Morikawa T, Naito A, et al. Optimal timing of salvage radiotherapy for biochemical recurrence after radical prostatectomy: is ultra-early salvage radiotherapy beneficial? Radiat Oncol. 2016;11(1):102.

\section{Submit your next manuscript to BioMed Central and we will help you at every step:}

- We accept pre-submission inquiries

- Our selector tool helps you to find the most relevant journal

- We provide round the clock customer support

- Convenient online submission

- Thorough peer review

- Inclusion in PubMed and all major indexing services

- Maximum visibility for your research

Submit your manuscript at www.biomedcentral.com/submit

Biomed Central 